\title{
Removal of Humic Acid by Photocatalytic Process: Effect of Light Intensity
}

\author{
Getkaew Pansamut ${ }^{1}$, Tawatchai Charinpanitkul ${ }^{2}$, and Achariya Suriyawong ${ }^{1, *}$ \\ 1 Department of Environmental Engineering, Faculty of Engineering, Chulalongkorn University, \\ Bangkok 10330, Thailand \\ 2 Department of Chemical Engineering, Faculty of Engineering, Chulalongkorn University, \\ Bangkok 10330, Thailand \\ *E-mail: achariya.s@eng.chula.ac.th (Corresponding author)
}

\begin{abstract}
Humic acid is commonly found in natural water as it is one of the by-products from decomposition of plants and animal residues. In a conventional water treatment process, which chlorine is common used as a disinfectant, the presence of humic acid could lead to the formation of carcinogenic substances, such as trihalomethanes and haloacetic acids. Thus, removal of humic acid from raw water before disinfection process is necessary. Photocatalytic reaction using Titanium Dioxide $\left(\mathrm{TiO}_{2}\right)$ as a photocatalyst is one of the most effective techniques for degrading humic acid. The efficiency of this process depends on several factors; and, one of these factors is light intensity. This research investigated the effect of light intensity $\left(35,225\right.$ and $\left.435 \mu \mathrm{W} / \mathrm{cm}^{2}\right)$ and studied the kinetic of photocatalytic degradation of humic acid, using commercial $\mathrm{TiO}_{2}$ Degussa P25 as a photocatalyst. The concentration of humic acid was monitored by using $\mathrm{UV}_{254}$ absorption technique and the concentration of total organic compound was measured using a Total Organic Carbon Analyzer (TOC) every $30 \mathrm{~min}$. The results showed that the removal efficiency of humic acid increased with increasing light intensity and then becoming asymptotic. At light intensity of $435 \mu \mathrm{W} / \mathrm{cm}^{2}$ and initial humic acid concentration of $4 \mathrm{mg} / \mathrm{L}$ with $\mathrm{TiO}_{2}$ loading of $100 \mathrm{mg} / \mathrm{L}$, the highest humic acid removal efficiency was found at $99 \%$; however, the removal efficiency of the total organic compound was found only $20 \%$-indicating incomplete mineralization to the end product. The kinetic of the humic acid degradation process was further explained using a Langmuir - Hinshelwood $(\mathrm{L}-\mathrm{H})$ model. The reaction rate constants $\left(k_{\mathrm{L}-\mathrm{H}}\right)$ at the light intensity of 35,225 and $435 \mu \mathrm{W} / \mathrm{cm}^{2}$ were $0.049,0.152$ and $0.178 \mathrm{mg} \mathrm{L}^{-1} \mathrm{~min}^{-1}$, respectively; while the adsorption coefficients $\left(K_{a d s}\right)$ were relatively unchanged with light intensity. These findings imply that light intensity has an effect only on the oxidation process.
\end{abstract}

Keywords: Humic acid, photocatalytic oxidation, titanium dioxide, light intensity.

ENGINEERING JOURNAL Volume 17 Issue 3

Received 31 January 2013

Accepted 5 June 2013

Published 1 July 2013

Online at http://www.engj.org/

DOI:10.4186/ej.2013.17.3.25 


\section{Introduction}

Humic acid, one of the major fractions of Natural Organic Matter (NOM) in natural water, is derived from microbial activity and decomposition of plant and animal residues. The presence of humic acid in water has been reported to cause color, odor, and taste problems in natural water [1]. In a conventional water treatment process, humic acid is known to react with chemical disinfectants, like chlorine or ozone, during disinfection process forming carcinogenic substance, such as trihalomethanes (THMs) and haloacetic acids (HAAs) [2]. Therefore, the removal of humic acid from natural water during water treatment process is important. At the presence, several techniques have been applied to remove humic acid from raw water, including coagulation [3], ozonation [4], membrane filtration [5] and ion-exchange [6]. Recently, Advance Oxidation Processes (AOPs) via chemical oxidation, such as ozone and hydrogen peroxide (with or without being photo-assisted), have been receiving attention in removing humic acid. Photocatalytic process using $\mathrm{TiO}_{2}$ as a photocatalyst is one of the most attractive processes because of its low-cost, environmental friendly and complete destruction of humic acid molecules by direct oxidation process [7]. When $\mathrm{TiO}_{2}$ photocatalyst is illuminated by UV radiation, electrons from the valence band is excited to the conduction band, leading to the production of highly oxidative holes on the valence band and the formation of radicals, in particular hydroxyl radical $[8,9]$. These holes on $\mathrm{TiO}_{2}$ surface and radicals in the bulk solution can oxidize organic compounds and results carbon dioxide $\left(\mathrm{CO}_{2}\right)$ when oxidation process is completed [10]. The efficiency of this process depends on several factors, including light intensity, wavelength, initial humic acid concentration and crystal structure of $\mathrm{TiO}_{2}$. Several researchers studied the photocatalytic treatment of humic acid. Liu et al. [1] investigated the photocatalytic removal of humic acid $(10 \mathrm{mg} / \mathrm{L})$ using $\mathrm{TiO}_{2}(0.1$ $\mathrm{g} / \mathrm{L})$ under UVA irradiation. The UVA $/ \mathrm{TiO}_{2}$ process was found to be effective in removing more than $90 \%$ of humic acid, measured by $\mathrm{UV}_{254}$ absorption technique after $150 \mathrm{~min}$ of photocatalytic treatment. Dziedzic et al. [11] studied the effects of wavelength on photocatalytic degradation using UV and artificial sunlight (ASL) and reported that the removal efficiency of humic acid under ASL irradiation was found only $18 \%$, whereas the removal under UV irradiation was found to be $100 \%$ measured by $\mathrm{UV}_{254}$ absorption technique. Wiszniowski et al. [12] studied the kinetics of photocatalytic degradation of humic acid (100 $\mathrm{mg} / \mathrm{L})$ using commercial $\mathrm{TiO}_{2}(0.1$ to $2 \mathrm{~g} / \mathrm{L})$, described the photodegradation rate as a first-order kinetics, and reported that the photodegradation rate was inversely proportional to $\mathrm{TiO}_{2}$ concentration. The latter finding was explained as the suspended particles of $\mathrm{TiO}_{2}$ block UV-light passage and reduced the formation of electron-hole pairs and active sites. Although there have been a number of studies the photocatalytic degradation of humic acid using $\mathrm{TiO}_{2}$, only a few studies examined the kinetics of photocatalytic degradation. Since light intensity is one of the key parameters influencing the photocatalytic degradation, this research aimed to investigate the effect of light intensity on the photocatalytic degradation of humic acid and examined its kinetic.

\section{Experimental}

\subsection{Materials}

Humic acid stock solution was prepared by mixing laboratory-grade humic acid solution (purchased from Sigma-Aldrich, Lot No. STBB1688V) with deionized water to conduct experiments at humic acid concentration of 4, 6, 8 and $10 \mathrm{mg} / \mathrm{L}$. Commercially available Titanium Dioxide P-25 type $\left(\mathrm{TiO}_{2}\right.$ Degussa P25), purchased from Sigma-Aldrich (Lot No. MKBG9739V) with its crystal structure comprising of approximately $80 \%$ anatase and $20 \%$ rultile and with a BET specific surface area of $50 \mathrm{~m}^{2} / \mathrm{g}$, was used as a photocatalyst at $\mathrm{TiO}_{2}$ loading of $0.1 \mathrm{~g} / \mathrm{L}$ for all experiments.

\subsection{Reactor Setup}

The photo-chemical experiments were performed in a $1 \mathrm{~L}$ cylindrical Pyrex beaker, and continuous stirring of the suspension was provided throughout the experiment using a magnetic stirrer. The reactor and the magnetic stirrer were placed in an acrylic box, which all inner walls were covered with aluminium foil. A 10 W UVA lamp, which emitted radiation wavelength between 315 and $400 \mathrm{~nm}$, was installed at the top of the box, and four of a $15 \mathrm{~W} \mathrm{UVA} \mathrm{lamps} \mathrm{were} \mathrm{installed} \mathrm{on} \mathrm{each} \mathrm{side} \mathrm{of} \mathrm{the} \mathrm{box.} \mathrm{At} \mathrm{the} \mathrm{location} \mathrm{where} \mathrm{the}$ reactor was placed in the box, the intensities of the incident light were measured using a UV light meter 
(UV-340B, Shenzhen). When only a $10 \mathrm{~W}$ UVA lamp was switched on, the measured light intensity was 35 $\mu \mathrm{W} / \mathrm{cm}^{2}$; when a $10 \mathrm{~W}$ UVA lamp and two of a $15 \mathrm{~W}$ UVA lamps were switched on, the measured light intensity was $225 \mu \mathrm{W} / \mathrm{cm}^{2}$; and when all the installed UVA lamps were switched on, the measured light intensity was $435 \mu \mathrm{W} / \mathrm{cm}^{2}$.

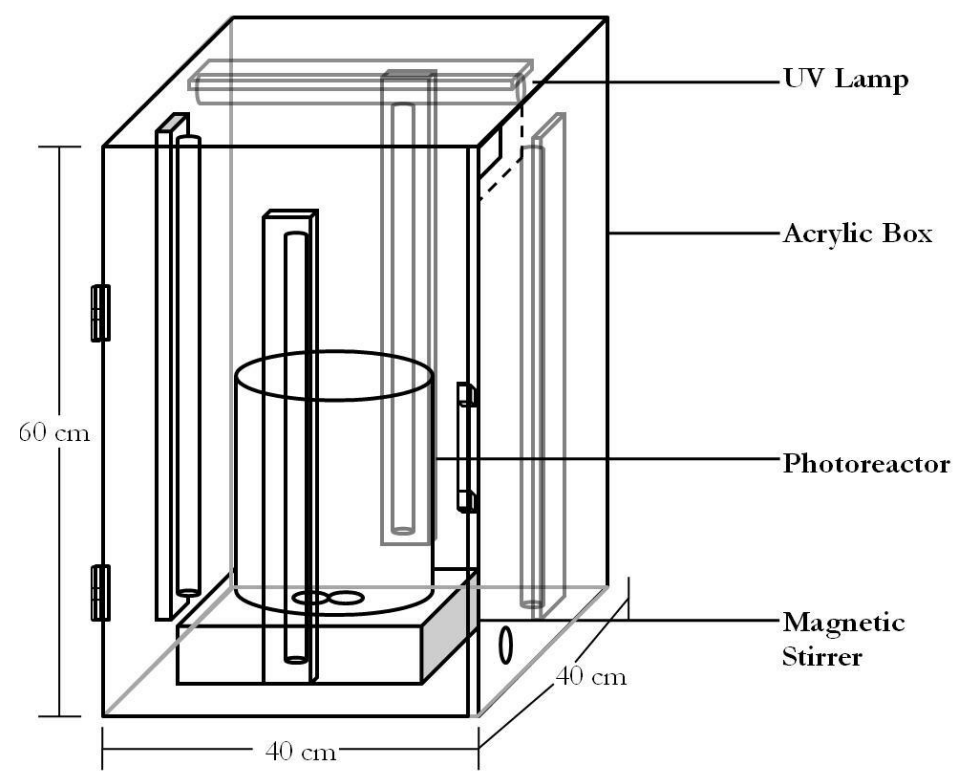

Fig. 1. Schematic of the photocatalytic reactor.

\subsection{Photocatalytic Experiments}

For each photocatalytic experiment, one liter humic acid solution (at the concentration of $4 \mathrm{mg} / \mathrm{L}$ for investigating the effect of light intensity on photocatalytic degradation of humic acid and at the concentration of 4, 6, 8 and $10 \mathrm{mg} / \mathrm{L}$ for evaluating its kinetic as a function of light intensity) was mixed with $\mathrm{TiO}_{2}$ at the concentration of $0.1 \mathrm{~g} / \mathrm{L}$ in a cylindrical Pyrex beaker, then the beaker was placed on a magnetic stirrer in the photoreactor. The oxidation process was initiated by turning on the UVA lamps. During the experiments, $60 \mathrm{ml}$ of samples were collected at 30 min interval, immediately filtered through $0.45 \mu \mathrm{m}$ membrane filter to remove $\mathrm{TiO}_{2}$ particles and stop the photocatalytic oxidation reactions, and measured concentrations of humic acid and total organic carbon. Concentration of humic acid was monitored by $\mathrm{UV}$ at $254 \mathrm{~nm}$ wavelength absorption technique $\left(\mathrm{UV}_{254}\right)$ using a UV-visible spectrophotometer (UV-1700, Shimadzu), and concentration of total organic compound was measured using a Total Organic Carbon (TOC) Analyzer (TOC V-CPH, Shimadzu).

\section{Results and Discussions}

In order to understand the influence of light intensity on photocatalytic degradation of humic acid, this research was carrying out in two parts. The first part investigated the effect of light intensity on the photocatalytic degradation of humic acid, and the second part evaluated the kinetic of the photocatalytic degradation as a function of light intensity.

\subsection{Effect of Light Intensity on Photocatalytic Degradation}

In this part of the research, experiments were conducted at different light intensities with initial humic acid concentration of $4 \mathrm{mg} / \mathrm{L}$ and $\mathrm{TiO}_{2}$ loading of $0.1 \mathrm{~g} / \mathrm{L}$, and concentrations of humic acid and total organic carbon were measured every $30 \mathrm{~min}$. The percentage of humic acid removal under the light intensity of 35 , 225 and $435 \mu \mathrm{W} / \mathrm{cm}^{2}$ are shown in Fig. 2. At light intensity of $35 \mu \mathrm{W} / \mathrm{cm}^{2}, 30 \mathrm{~min}$ after irradiation the removal of humic acid was found to be $27 \%$, then removal efficiency increased with time and reached about $70.6 \%$ at $150 \mathrm{~min}$. At light intensity of $225 \mu \mathrm{W} / \mathrm{cm}^{2}, 30 \mathrm{~min}$ after irradiation the removal of humic acid was found to be $82.8 \%$, then removal efficiency slowly increased with time and reached about $94.7 \%$ at 
$150 \mathrm{~min}$. At light intensity of $435 \mu \mathrm{W} / \mathrm{cm}^{2}, 30 \mathrm{~min}$ after irradiation the removal efficiency reached $94.8 \%$, then removal efficiency slowly increased with time, and reached about $99 \%$ at $150 \mathrm{~min}$. The highest humic acid removal efficiency was found at the highest light intensity used in this study $\left(435 \mu \mathrm{W} / \mathrm{cm}^{2}\right)$. This result could be attributed to the electron-hole-pair generation rate. When incident light with sufficient energy to overcome the catalyst band gap falls on the surface of a photocatalyst, the electron in the valence band jumps to the conduction band, resulting in the generation of a positive hole and a free radical. And, during this electron-hole pair generation, oxidation-reduction reactions take place [13]. Higher intensity of the incident light, which has sufficient-energy, would lead to higher electron-hole pair generation rate, and subsequently higher photo-catalytic activity, resulting in higher removal efficiency. This finding indicates that light intensity is one of the important factors influencing photocatalytic degradation of humic acid.

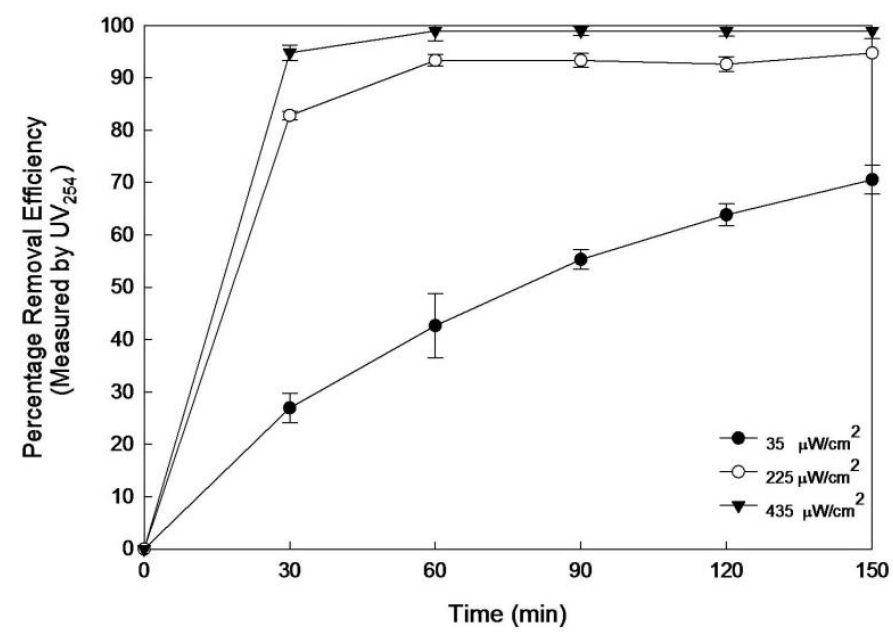

Fig. 2. Humic acid removal efficiency (measured by $\mathrm{UV}_{254}$ absorption technique) under the light intensity of 35,225 and $435 \mu \mathrm{W} / \mathrm{cm}^{2}$ with initial humic acid concentration $\left(C_{0}\right)$ of $4 \mathrm{mg} / \mathrm{L}$.

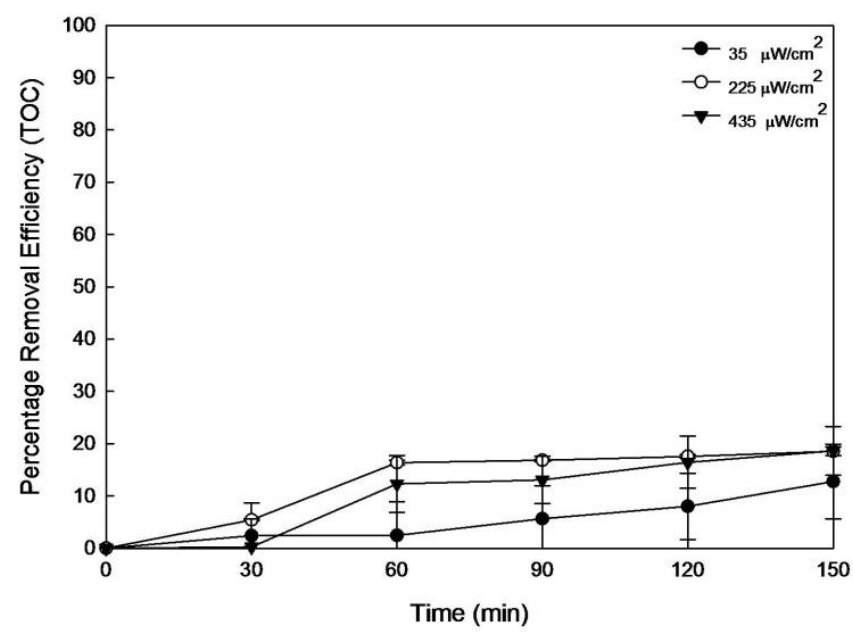

Fig. 3. Total organic carbon removal efficiency under the light intensity of 35,225 and $435 \mu \mathrm{W} / \mathrm{cm}^{2}$ with initial humic acid concentration of $4 \mathrm{mg} / \mathrm{L}$.

During the experiments, total organic carbon was also measured along with humic acid concentration in all collected samples. Total organic carbon is the amount of carbon bound in an organic compound, which in this study used as the other indicator for monitoring oxidation-reduction reactions of humic acid. The percentage of TOC removal under the light intensity of 35,225 and $435 \mu \mathrm{W} / \mathrm{cm}^{2}$ with initial humic acid concentration of $4 \mathrm{mg} / \mathrm{L}$ and $\mathrm{TiO}_{2}$ loading of $0.1 \mathrm{~g} / \mathrm{L}$ are shown in Fig 3. At light intensity of 35 $\mu \mathrm{W} / \mathrm{cm}^{2}$, $60 \mathrm{~min}$ after irradiation the removal of TOC was found to be $2.4 \%$, then removal efficiency increased with time, and reached about $12.8 \%$ at $150 \mathrm{~min}$. At light intensity of $225 \mu \mathrm{W} / \mathrm{cm}^{2}, 60$ 
min after irradiation the removal of TOC was found to be $16.4 \%$, which is much higher than that of 35 $\mu \mathrm{W} / \mathrm{cm}^{2}$ light intensity, then removal efficiency slightly increased with time, and reached about $18.5 \%$ at $150 \mathrm{~min}$. At light intensity of $435 \mu \mathrm{W} / \mathrm{cm}^{2}, 60 \mathrm{~min}$ after irradiation the removal of TOC was found to be $12.3 \%$, then removal efficiency increased with time and reached about $19.6 \%$ at $150 \mathrm{~min}$. When comparing the TOC removal efficiency with the humic acid removal efficiency, it should be noted that the humic acid removal rapidly occurred within the first thirty minute after irradiation, while the TOC removal arose in the first $60 \mathrm{~min}$ of irradiation; and after $150 \mathrm{~min}$ of irradiation TOC removal efficiency was approximately $20 \%$, which is much lower than the humic acid removal efficiency (about 95\%). This indicates that that the intermediate compounds were formed after the oxidation process, and incomplete mineralisation of humic acid to the end product in form of $\mathrm{CO}_{2}$ occured [1].

\subsection{The Kinetics of Photocatalytic Degradation}

The previous part of this study investigated the effect of light intensity on the photocatalytic degradation of humic acid, and the results indicated that light intensity plays an important role on the degradation of humic acid. The second part of this study aims to evaluate its kinetic since understanding kinetic of this process would allow appropriate design when this technique is applied in water-treatment systems. The experiments were conducted at different initial humic acid concentration $(4,6,8$ and $10 \mathrm{mg} / \mathrm{L})$ and light intensity $\left(35,225\right.$ and $435 \mu \mathrm{W} / \mathrm{cm}^{2}$ ) with a fixed $\mathrm{TiO}_{2}$ loading of $0.1 \mathrm{~g} / \mathrm{L}$. Since the photcatalytic degradation of humic acid involves the adsorption of the substance on the catalyst surface and the chemical reaction to convert the compounds into carbon dioxide and water, the Langmuir-Hinshelwood (L-H) model, which covers both the adsorption step and chemical reaction step, was selected to discuss the kinetic of this photocatalytic process [14]. The L-H kinetic model can be described as following:

$$
R=-\frac{d C}{d t}=\frac{k_{L-H} K_{a d s} C_{0}}{1+K_{a d s} C_{0}}
$$

$k_{\mathrm{L}-\mathrm{H}}$ is the reaction rate constant, $\mathrm{mg} \mathrm{L}^{-1} \mathrm{~min}^{-1} ; K_{\mathrm{ads}}$ is the adsorption coefficient of the substance on the surface of $\mathrm{TiO}_{2}$ particles, $\mathrm{L} \mathrm{mg}^{-1} ; C$ is the concentration of humic acid, $\mathrm{mg} \mathrm{L}^{-1} ; C_{0}$ is the initial concentration of humic acid, mg $\mathrm{L}^{-1}$.

Integration of Eq. (1) yields the following equation:

$$
\ln \left(\frac{C}{C_{0}}\right)+K_{a d s}\left(C_{0}+C\right)=k_{L-H} K_{a d s} t
$$

Then, the half-life $\left(t_{1 / 2}\right)$, the time at which the remaining concentration of humic acid is half of the initial concentration, can be deduced as

$$
t_{1 / 2}=\left(\frac{0.693}{k_{\mathbf{L}-H} K_{a d s}}\right)+\left(\frac{0.5}{k_{L-H}}\right) C_{0}
$$

By plotting $t_{1 / 2}$ versus $C_{0}$ should give a straight line with a slope of $0.5 / k_{\mathrm{L}-\mathrm{H}}$ and an intercept of $0.693 / k_{\mathrm{L}-\mathrm{H}} K_{\mathrm{ads}}$, and through which the coefficients $k_{\mathrm{L}-\mathrm{H}}$ and $K_{\mathrm{ads}}$ can be calculated. When the initial concentration $C_{0}$ is small, Eq. (2) can be simplified to a pseudo-first order reaction as shown in Eq. (4).

$$
\ln \left(\frac{C}{C_{0}}\right)=k_{L-H} K_{a d s} t=k t \text { or } C_{t}=C_{0} e^{-k t}
$$

yielding half-life, $\mathrm{t}_{1 / 2}(\mathrm{~min})$

$$
t_{1 / 2}=\frac{0.693}{k}
$$


where $k$ is the pseudo-first-order reaction rate constant, and $k=k_{L-H} K_{a d s}, \min ^{-1}$.

From experimental results, the observed degradation of humic acid followed an exponential decay form for all initial humic acid concentrations evaluated in this study; the example of the decay (at the initial humic acid concentration of $6 \mathrm{mg} / \mathrm{L}$ ) is depicted in Fig. 4. At light intensity of $35 \mu \mathrm{W} / \mathrm{cm}^{2}$, after $30 \mathrm{~min}$ of irradiation the remaining fraction of humic acid in the solution was 0.63 , then decreased with time, and reached about 0.31 after $150 \mathrm{~min}$ irradiation. At light intensity of $225 \mu \mathrm{W} / \mathrm{cm}^{2}, 30 \mathrm{~min}$ after irradiation the remaining of humic acid concentration was 0.52 and reached about 0.06 at 150 min after irradiation. At light intensity of $435 \mu \mathrm{W} / \mathrm{cm}^{2}, 30$ min after irradiation the remaining of humic acid was 0.19 and reached about 0.05 at $150 \mathrm{~min}$ after irradiation. Among the experiments, the highest of humic acid removal was found at light intensity of $435 \mu \mathrm{W} / \mathrm{cm}^{2}$, and the lowest humic acid removal was found at light intensity of $35 \mu \mathrm{W} / \mathrm{cm}^{2}$. Although the humic acid removal at light intensity of $225 \mu \mathrm{W} / \mathrm{cm}^{2}$ and $435 \mu \mathrm{W} / \mathrm{cm}^{2}$ after 120 min irradiation were similar, it should be noted that humic acid degradation at the light intensity of 435 $\mu \mathrm{W} / \mathrm{cm}^{2}$ was much faster in the first 60 min, suggesting the influence of light intensity on the degradation rate of humic acid.

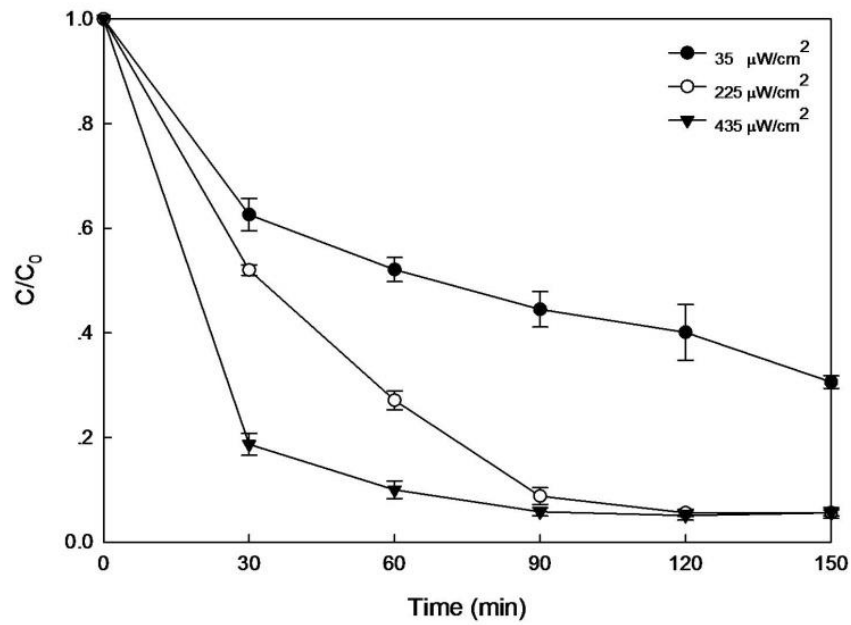

Fig. 4. Photocatalytic degradation of humic acid (initial humic acid concentration $\left(C_{0}\right)$ of $6 \mathrm{mg} / \mathrm{L}$ ) under the light intensity of 35,225 and $435 \mu \mathrm{W} / \mathrm{cm}^{2}$.

As a simplified L-H rate equation (Eq. (1)) renders a simple pseudo-first-order kinetic equation (Eq. (4)), $k$ values could be deduced from a slope of $\ln \left(\mathrm{C} / \mathrm{C}_{0}\right)$ versus irradiation time plot, as shown in Fig. 5 , and the half-life values at different light intensities and at different initial concentrations $(4,6,8$ and 10 $\mathrm{mg} / \mathrm{L}$ ) can be calculated from Eq. (5). By plotting the half-life values at different light intensity, calculated from Eq.(5), versus the initial humic acid concentration $\left(C_{0}\right)$, as shown in Fig. 6, the kinetic constants can be determined and reported in Table 1 . The reaction rate constant $\left(k_{\mathrm{L}-\mathrm{H}}\right)$ for the light intensity of 35,225 and $435 \mu \mathrm{W} / \mathrm{cm}^{2}$ were $0.049,0.152$ and $0.178 \mathrm{mg} \mathrm{L}^{-1} \mathrm{~min}^{-1}$, and the adsorption coefficient $\left(K_{\text {ads }}\right)$ values were found to be $0.399,0.363$ and $0.430 \mathrm{~L} \mathrm{mg}^{-1}$, respectively. The values of $k_{\mathrm{L}-\mathrm{H}}$ and $K_{a d s}$ at the light intensity of $35 \mu \mathrm{W} / \mathrm{cm}^{2}$ were within the same order of magnitude as those reported by Bekbolet et al. [14]. It should be noted that the $k_{\mathrm{L}-\mathrm{H}}$ values increased with light intensity, while the $K_{a d s}$ values were relatively unchanged $( \pm 20 \%)$ when increasing light intensity. This indicates the influence of light intensity on humic acid oxidation process, but not the adsorption. The inclined trend of the reaction rates when light intensity increased further implies that the photo-degradation of humic acid is a function of light intensity-the higher the light intensity, the faster the degradation rate-thus, requiring less time. In addition, when considering the changing in values of $k_{\mathrm{L}-\mathrm{H}}$ and $K_{a d s}$ with light intensity, it could be inferred that the oxidation process is the rate limiting step in this photo-catalytic degradation. 


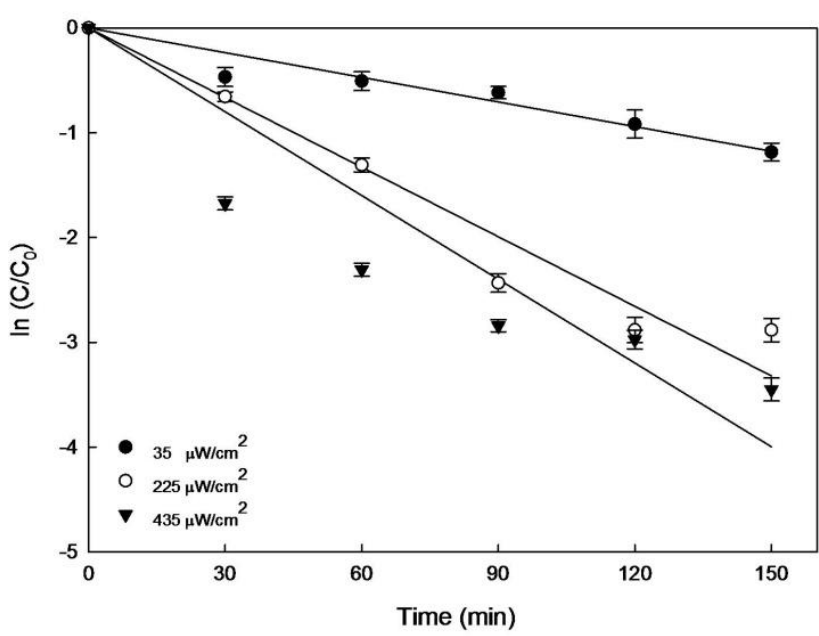

Fig. 5. First-order kinetic of humic acid photocatalytic degradation under the light intensity of 35, 225 and $435 \mu \mathrm{W} / \mathrm{cm}^{2}$ at the initial humic acid concentration $\left(C_{0}\right)$ of $6 \mathrm{mg} / \mathrm{L}$.

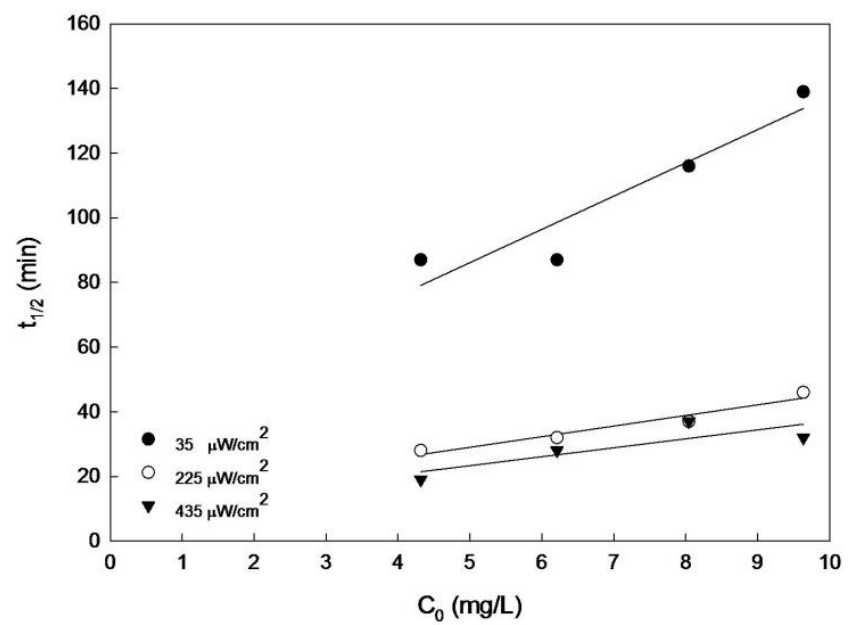

Fig. 6. L-H kinetic of humic acid photocatalytic degradation under the light intensity of 35, 225 and 435 $\mu \mathrm{W} / \mathrm{cm}^{2}$.

Table 1. L-H kinetic parameters.

\begin{tabular}{|c|c|c|c|c|c|}
\hline $\begin{array}{l}\text { Light intensity } \\
\left(\mu \mathrm{W} / \mathrm{cm}^{2}\right)\end{array}$ & 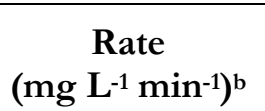 & $\begin{array}{c}t_{1 / 2} \\
(\min )^{b}\end{array}$ & 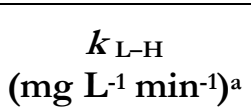 & $\begin{array}{c}K_{a d s} \\
(\mathrm{~L} / \mathrm{mg})^{a}\end{array}$ & $R^{2}$ \\
\hline 35 & 0.035 & 0.049 & 0.399 & 99 & 0.87 \\
\hline 225 & 0.105 & 0.152 & 0.363 & 33 & 0.95 \\
\hline 435 & 0.130 & 0.178 & 0.430 & 27 & 0.82 \\
\hline
\end{tabular}

a $k_{L H H}$ and $K_{a d s}$ were calculated from the slope and interception of the plots in Fig. 6 at the initial humic acid concentration ranging between 4 and $10 \mathrm{mg} / \mathrm{L}$.

${ }^{b}$ Examples of the rates and the half-life $\left(t_{1 / 2}\right)$ calculated at the initial humic acid concentration of $6 \mathrm{mg} / \mathrm{L}$.

\section{Conclusion}

This research investigated the effect of light intensity $\left(35,225\right.$ and $\left.435 \mu \mathrm{W} / \mathrm{cm}^{2}\right)$ on photocatalytic degradation of humic acid using $\mathrm{TiO}_{2}$ as a photocatalyst, and evaluated its kinetic. The results showed that the removal efficiency of humic acid increased with increasing light intensity, and then becoming asymptotic. The highest humic acid removal efficiency $\left(99 \%\right.$ removal measured by $\mathrm{UV}_{254}$ absorption 
technique) was found at the light intensity of $435 \mu \mathrm{W} / \mathrm{cm}^{2}$ and at humic acid concentration of $4 \mathrm{mg} / \mathrm{L}$; however, under the same condition the removal efficiency of total organic compound was found only $20 \%$, implying the partial oxidation of humic acid and the formation of intermediate compounds. For kinetic evaluation using the Langmuir-Hinshelwood model, the values of reaction rate constant $\left(k_{\mathrm{L}-\mathrm{H}}\right)$ were found to increase with light intensity, while the values of adsorption coefficient $\left(K_{\text {ads }}\right)$ were relatively unaltered when light intensity increased. This indicates the influence of light intensity on humic acid oxidation process, not the adsorption step. Furthermore, the increase of the reaction rates with light intensity implies that light intensity is one of the important parameters influencing the photo-degradation of humic acid using $\mathrm{TiO}_{2}$.

\section{Acknowledgment}

This work was partially supported by the grants from Faculty of Engineering (Engineering Research Grant), Chulalongkorn University, 90th Anniversary of Chulalongkorn University Fund, 100 th Anniversary of Chula Engineering 2013, and National Research Council of Thailand Scholarship.

\section{References}

[1] S. Liu, M. Lim, R. Fabris, C. Chow, K. Chiang, M. Drikas, and R. Amal, "Removal of humic acid using $\mathrm{TiO}_{2}$ photocatalytic process - Fractionation and molecular weight characterisation studies," Chemosphere, vol. 72, pp. 263-271, 2008.

[2] X. Huang, M. Leal, and Q. Li, "Degradation of natural organic matter by $\mathrm{TiO}_{2}$ photocatalytic oxidation and its effect on fouling of low-pressure membranes," Water Res., vol. 42, pp. 1142-1150, 2007.

[3] V. Uyak, and I. Toroz, "Disinfection by-product precursors reduction by various coagulation techniques in Istanbul water supplies," J. Hazard. Mater., vol. 141, pp. 320-328, 2007.

[4] B. S. Sobecka, M. Tomaszewska, and A. W. Morawski, "Removal of humic acids by the ozonationbiofiltration process," Desalination, vol. 198, pp. 265-273, 2006.

[5] J. J. Qin, M. H. Oo, and Y. Li, "Hollow fiber ultrafiltration membranes with enhanced flux for humic acid removal," J. Membrane Sci., vol. 247, pp. 119-125, 2005.

[6] B. Bolto, D. Dixon, and R. Eldridge, "Ion exchange for the removal of natural organic matter," React. Funct. Polym., vol. 60, pp. 171-182, 2004.

[7] M. Ni, M. K. H. Leung, D. Y.C. Leung, and K. Sumathy, "A review and recent developments in photocatalytic water-splitting using $\mathrm{TiO}_{2}$ for hydrogen production," Renew. Sust. Energ. Rev., vol. 11, pp. 401-425, 2007.

[8] O. Carp, C. L. Huisman, and A. Reller, "Photoinduced reactivity of titanium dioxide," Prog. Solid State, vol. 32, pp. 33-177, 2004.

[9] M. Sokmen, D. W. Allen, and M. R. Clench, "Photocatalytic oxidative degradation of 2-methylthiophene in suspensions of TiO2: Identification of intermediates and degradation pathways," J. Photochem. Photobiol., vol. 141, pp. 63-67, 2001.

[10] K. Hashimoto, H. Irie, and A. Fujishima, " $\mathrm{TiO}_{2}$ photocatalysis: A Historical overview and future prospects," Jpn. J. Appl. Phys., vol. 44, no. 12, pp 8269-8285, 2005.

[11] J. Dziedzic, D. Wodka, P. Nowak, P. Warszyński, S. C. Rone, and K. Izumi, "Photocatalytic degradation of the humic species as a method of their removal from water - Comparison of UV and artificial sunlight (ASL) irradiation," Physicochem. Probl. Miner. Process., vol. 45, pp. 15-28, 2010.

[12] J. Wiszniowski, D. Robert, J. Surmacz-Gorska, K. Miksch, and J.-V. Weber, "Photocatalytic decomposition of humic acids on $\mathrm{TiO}_{2}$ Part I: Discussion of adsorption and mechanism," J. Photochem. Photobiol., vol. 152, pp. 267-273, 2002.

[13] W. Zhang, Y. Li, C. Wang, and P. Wang, "Kinetics of heterogeneous photocatalytic degradation of rhodamine $\mathrm{B}$ by $\mathrm{TiO}_{2}$-coated activated carbon: Roles of $\mathrm{TiO}_{2}$ content and light intensity," Desalination, vol. 266, pp. 40-45, 2011.

[14] M. Bekbolet, A. S. Suphandag, and C. S. Uyguner, "An investigation of the photocatalytic efficiencies of $\mathrm{TiO}_{2}$ powders on the decolourisation of humic acids," J. Photochem. Photobiol., vol. 148, pp. 121-128, 2002. 